\title{
EU Immigrant Integration Policies and Returns on Human Capital
}

\author{
Raul Ramos, Alessia Matano and Sandra Nieto ${ }^{1}$
}

\begin{abstract}
In order to address skill shortages and the demographic challenges facing the EU, member states have to attract (and retain) the more skilled migrants. Nevertheless, foreign residents generally find a significant wage gap with respect to native-born workers when arriving in a host country. Favourable integration policies seem to improve the relative performance of immigrants in the labour market. Indeed, analysis of the role of favourable or unfavourable policies in supporting labour market mobility of recently arrived immigrants shows that wage discrimination between immigrants and natives is lower in those countries with more favourable policies and that this lower gap is associated with higher returns on experience and schooling.
\end{abstract}

Keywords: Migration policy, labour market integration, immigrants, returns on human capital.

\footnotetext{
${ }^{1}$ Raul Ramos, Alessia Matano and Sandra Nieto are researchers at AQR-IREA, Universitat de Barcelona. Sandra Nieto is also researcher at the Universitat Oberta de Catalunya. Emails: rramos@ub.edu; amatano@ub.edu; snietov@uoc.edu. The research leading to these results received funding from the European Community's Seventh Framework Programme (FP7/2010-2.2-1) under grant agreement no 266834. Microdata from the European Commission, Eurostat, cross-sectional EU-SILC 2004 to 2012 database were made available by Eurostat under contract EU-SILC/2012/17. Eurostat has no responsibility for the results and conclusions reported here. The authors thank the editor, Gabriele Tonne, and two anonymous referees for helpful comments and suggestions. The usual disclaimer applies.
} 
As recognised in the Europe 2020 strategy, the European Union (EU) faces a clear demographic challenge in the next decades. The EU will need to import foreign labour in response to gloomy demographic forecasts in the context of ageing populations, low birth rates, and the prospects of a collapsing social security system. Improving the situation of immigrants in the labour markets is also an important challenge for the EU member states. These are probably two of the reasons why the latest EU Commission created the new post of Commissioner for Migration. It is not clear, however, whether Commissioner Dimitris Avramopoulos has new responsibilities and duties or whether the Home Affairs folder has just been renamed to emphasise its migration responsibilities. In any case, in his mission letter addressed to Avramopoulos, the President of the Commission affirms that:

Migration is one of the pressing challenges I have highlighted in my Political Guidelines. Europe needs to manage migration better, in all its aspects. A successful migration policy is both a humanitarian and an economic imperative. We need to show that the EU can offer both a compelling case to attract global talent, and a vision of how to robustly address the challenge of irregular migration. We need a new policy on migration that will address skill shortages and the demographic challenges the EU faces and that will modernise the way the EU addresses these challenges. ${ }^{2}$

The mission letter clearly states the need to focus on addressing skills shortages and attracting talent. This topic has played a central role in numerous studies carried out in recent decades on the subject of international migration and its consequences. ${ }^{3}$ Both academics and policymakers have placed particular attention on the wage gap between immigrants and native-born workers. The findings of this literature are twofold: first, immigrants typically face a significant wage gap when arriving in the host country and, second, this gap tends to diminish the longer they remain in their host country. Initial differences in wage levels are related to the imperfect transferability of human capital to the new labour market, while the rapid growth over time in immigrant wage levels is related to their accumulation of different types of human capital in the host country, which is particularly significant in the first years of residence in the host country. ${ }^{4}$

\footnotetext{
${ }^{2}$ http://ec.europa.eu/about/juncker-commission/docs/avramopoulos en.pdf

3 Mahroum, "Europe and Immigration", 29; Chaloff and Lemaïtre, Managing Highly-Skilled Labour Migration, 10; Docquier and Machado, "Global competition for attracting talents", 1.

4 Jean et al., "Migration and Labour Market Outcomes", 15; Amuedo-Dorantes and De la Rica, "Labour market assimilation in Spain", 269; Borjas, Assimilation, Changes in Cohort Quality and the Earnings of Immigrants, 464.
} 
The aim of this article is to test these findings, especially those regarding the return on education and experience, and to analyse the role of favourable or unfavourable policies for supporting the labour market mobility of immigrants. ${ }^{5}$ This is done by quantifying wage differences between native and immigrant workers in EU countries, giving special attention to returns on human capital. Our hypothesis is that wage gaps will be lower in those countries with more favourable policies due to higher returns on human capital. In particular, not all foreign residents with the right to work have equal access to the full labour market, education system or employment services. For instance, only nationals and EU nationals in Europe enjoy equal opportunities in the public sector and better procedures to recognise their non-EU degrees.

In order to identify differences in these policy frameworks, the Migrant Integration Policy Index (MIPEX) 1.3 index was used, which focuses on "Targeted Support for Labour Mobility". ${ }^{6}$ Targeted support policies are related to academic recognition procedures, targeted workrelated training, specific bridging/work placement programmes and employment mentors/coaches for newcomers. This index goes from 0 to 100 , with lower values indicating more unfavourable policy frameworks for immigrants. As shown in Table 1, according to these data, between 2007 and 2010 nearly all new EU member states (EU-13) had unfavourable policies, while the old EU member states (EU-15) formed two clear groups: one made up of Austria, Belgium, Greece, Ireland, Italy, Luxemburg and the United Kingdom with less favourable policies, and the other made up of Germany, Denmark, Spain, Finland, France, Netherlands, Portugal and Sweden where policies were more favourable. Table 2 shows that between 2007 and 2010 the situation was fairly stable. In fact, only Austria changed from less favourable to more favourable policies in that period. The fact that these policies remained unchanged makes it possible to use this classification for analysis.

Taking this as the basis, the idea is to test whether the wage gap is narrower in countries with more favourable policies than in those with less favourable ones and, then, if returns on human capital (formal education and experience) make a difference.

\footnotetext{
5 Psacharopoulos, "Returns to investment in education"; Psacharopoulos and Patrinos, "A further update"; Friedberg, "You can't take it with you"; Dustman and Glitz, "Migration and Education".

${ }^{6}$ http://www.mipex.eu/
} 
Table 1. Different policy frameworks supporting labour market mobility

\begin{tabular}{|c|c|c|}
\hline $\begin{array}{l}\text { MIPEX 1.3. TARGETED SUPPORT } \\
\text { FOR LABOR MARKET MOBILITY } \\
\text { (average value 2007-10) }\end{array}$ & EU15 & EU13 \\
\hline $\begin{array}{l}\text { Critically unfavourable (0) } \\
\text { Unfavourable (1-20) } \\
\text { Slightly Unfavourable (21-40) }\end{array}$ & $\begin{array}{c}\text { EL (0), } \\
\text { LU (6.3), IE (18.8), } \\
\text { AT (25), IT (25.0), UK (25), BE (37.5) }\end{array}$ & $\begin{array}{c}\text { SK (0), } \\
\text { CY (12.5), CZ (12.5), LV (12.5),MT (12.5), } \\
\text { PL (12.5), HU (12.5), HR(13), SI (18.8), } \\
\text { BG (25), LT (25), RO (37.5) }\end{array}$ \\
\hline $\begin{array}{l}\text { Halfway favourable (41-59) } \\
\text { Slightly favourable (60-79) } \\
\text { Favourable (80-100) }\end{array}$ & $\begin{array}{c}\text { ES (50), PT (56.3), } \\
\text { FI (62.5) FR (62.5), DK (68.8), NL (75), } \\
\text { DE (87.5), SE (100) }\end{array}$ & $\mathrm{EE}(62.5)$ \\
\hline
\end{tabular}

Austria (AT); Belgium (BE); Bulgaria (BG); Cyprus (CY); Czech Republic (CZ); Germany (DE); Denmark (DK); Estonia (EE); Greece (EL); Spain (ES); Finland (FI); France (FR); Croatia (HR), Hungary (HU); Ireland (IE); Italy (IT); Lithuania (LT); Luxembourg (LU); Latvia (LV); Malta (MT); Netherlands (NL); Poland (PO); Portugal (PT); Romania (RO); Sweden (SE); Slovenia (SI); Slovak Republic (SK); United Kingdom (UK).

Source: Own elaboration from MIPEX data, only available for the period 2007-10.

Table 2. Changes in policy frameworks supporting labour market mobility between 2007 and 2010

\begin{tabular}{|l|r|r|}
\hline $\begin{array}{l}\text { MIPEX 1.3. TARGETED SUPPORT } \\
\text { FOR LABOR MARKET MOBILITY } \\
\text { Change between 2007 and 2010 }\end{array}$ & EU15 & EU13* \\
\hline Unfavourable change & $\mathrm{IE} \mathrm{(-12.5)}$ & $\mathrm{SI}(-12.5)$ \\
\hline No significant change & $\mathrm{BE}, \mathrm{DE}, \mathrm{ES}, \mathrm{FI}, \mathrm{FR}$, & $\mathrm{CY}, \mathrm{CZ}, \mathrm{EE}, \mathrm{HU}$, \\
$\mathrm{EL}, \mathrm{IT}, \mathrm{NL}, \mathrm{SE}, \mathrm{UK}$ & $\mathrm{LV}, \mathrm{MT}, \mathrm{PL}, \mathrm{SK}$ \\
\hline Favourable change & $\mathrm{LU}(12.5), \mathrm{PT}(37.5), \mathrm{DK}(37.5), \mathrm{AT}(50)$ & \\
\hline
\end{tabular}

Austria (AT); Belgium (BE); Bulgaria (BG); Cyprus (CY); Czech Republic (CZ); Germany (DE); Denmark (DK); Estonia $(\mathrm{EE})$; Greece (EL), Spain (ES); Finland (FI); France (FR); Hungary (HU); Ireland (IE); Italy (IT); Lithuania (LT); Luxembourg (LU); Latvia (LV); Malta (MT); Netherlands (NL); Poland (PO); Portugal (PT); Romania (RO); Sweden (SE); Slovenia (SI); Slovak Republic (SK); United Kingdom (UK).

*Data for Bulgaria (BG), Croatia (HR) and Romania (RO) not available in 2007.

Source: Own elaboration from MIPEX data, only available for the period 2007-10.

Analysis of the impact of migration policies is not an easy task. As surveyed by Czaika and de Haas, "the scarce quantitative empirical literature finds rather unambiguous evidence that restrictive immigration policy measures do have significant effects on the magnitude and composition of immigration flows targeted by such policies". ${ }^{7}$ So far, empirical tests on the effectiveness of policy interventions, or more precisely, their qualitative-directional and quantitative-numerical effects on stocks or flows of different types of migrants, have basically looked at the situation before and after changes in policy. A similar approach was used in this study but not looking at the time variation of policies within a single country but considering cross-country differences in the policy framework. For this reason, separate analyses were

\footnotetext{
${ }^{7}$ Czaika and De Haas, The effectiveness of immigration policies, 1.
} 
carried out for the two different groups of countries with different labour mobility policies, distinguishing between EU member states with favourable and less favourable policies and between immigrants from other EU countries and from non-EU countries.

The rest of the article is structured as follows: first, data sources used in the empirical analysis are described; next, the results obtained are presented and discussed, while the last section concludes with some final remarks.

\section{Data sources and descriptive evidence}

For the analysis, the most recent EU Statistics on Income and Living Conditions (EU-SILC) were used, which provide comparable microdata for the $28 \mathrm{EU}$ member states. ${ }^{8}$ EU-SILC provides information on three broad categories of country of birth: country of residence, other EUcountry and non-EU country. ${ }^{9}$ It also gives detailed information on education, wages and other personal and job characteristics, making it an appropriate data set for this study. Analysis was focused on employees between 16 and 65 years of age, not currently involved in education.

For the analysis related to human capital, attention was focused on the role of formal education but also on potential experience. Regarding formal education, the information on educational levels available in the EU-SILC were converted into schooling years. Following the same approach, potential experience was calculated as the age of the individual minus schooling years minus $6 .{ }^{10}$

\footnotetext{
8 In particular, the EU-SILC cross-sectional files for 2004, 2005, 2006, 2007, 2008, 2009, 2010, 2011 and 2012 were used. Although the analysis could have been limited to the 2007-10 period covered by the MIPEX dataset, the sample size of EU-SILC is very limited, so taking into account that the two groups of countries remained constant, all available data were used in order to increase the reliability of results.

${ }_{9}^{9}$ Moreover, for five countries (Germany, Estonia, Latvia, Malta and Slovenia), only the resident and non-resident categories are given without no possibility of separating immigrants arriving from other EU countries and those arriving from non-EU countries.

10 One shortcoming of the EU-SILC database is that it does not provide information about age upon arrival in the host countries, data which would have made it possible to calculate years since migration and to differentiate actual experience in the home and in the host countries.
} 


\section{The wage gap between immigrant and native workers}

Figure 1 shows the result of the estimate of the native-immigrant wage gap. ${ }^{11}$ According to this estimate, the average wage gap between immigrant and natives is above 12 percent in EU-28. This means that an immigrant worker, identical to a native in terms of all observable characteristics considered will earn 12 percent less. This differential is similar when excluding Germany, Estonia, Latvia, Malta and Slovenia (EU23) as only the resident and non-resident categories are given, but higher than in the EU15. The figure also shows that, both in EU23 and EU15, the wage differential between native and immigrants is substantially higher for those coming from non-EU countries than for those coming from other EU countries. In particular, the wage gap for this group is 15 percent in EU23 and 12 percent in EU15 while for those coming from other EU countries it is below half that value, 7 percent in both cases.

Figure 1. Wage differential between native and immigrant workers

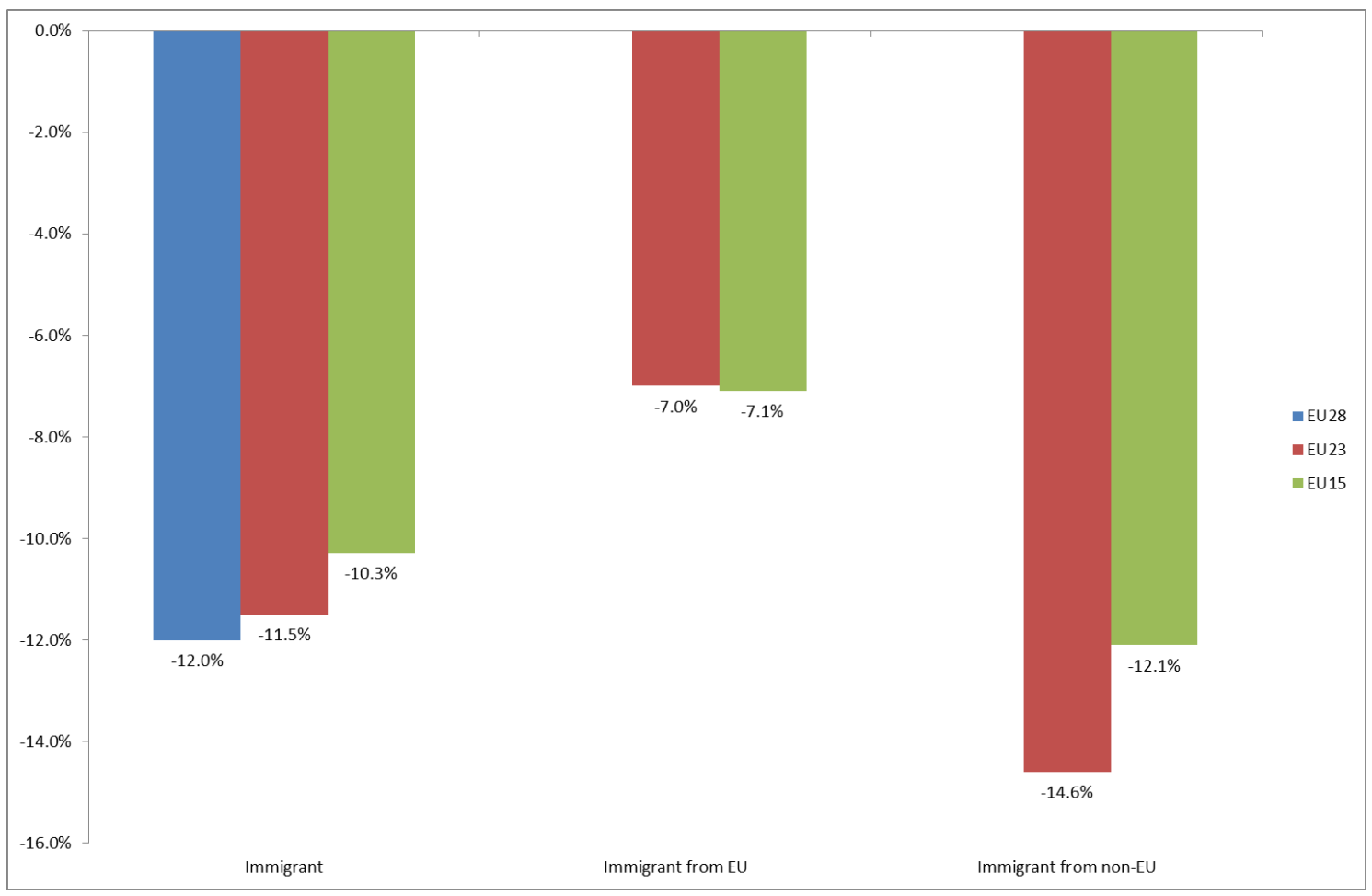

The wage gap in relation to more or less favourable policies

11 The methodology used in this section to analyse the native-immigrant wage gap is a multiple linear regression model where the logarithm of individual wages $\left(w_{i}\right)$ are explained by the fact of being migrant $\left(\right.$ migr $\left._{i}\right)$, the potential experience of the individual measured in years $\left(\right.$ potexp $\left._{i}\right)$ and the number of years of schooling $\left(s{ }_{i}\right)$. Additional variables that have an influence on wages such as gender, marital status, household size, dependent children, part time/full time and permanent/temporary contracts $\left(X_{i}\right)$ are also included as controls, together with a random error term $\left(\varepsilon_{i}\right)$. Descriptive statistics for main variables in the analysis and full details of the quantitative analysis are provided in the working paper version that can be downloaded from the following website:

http://www.ub.edu/searchproject/wp-content/uploads/2013/01/WP 3 7.pdf 
In order to test if this difference could be related to better integration policies, Figure 2 shows the results of splitting the sample between those immigrants residing in EU countries with more favourable and less favourable policies. Looking at Figure 2, it can be seen that wage differentials between native and immigrants are lower in those countries with more favourable policies than in those with less favourable policies: 2 percent and 10 percent for immigrants from other EU countries and 9 percent and 18 percent, respectively.

Figure 2. Wage differential between native and immigrant workers in relation to more or less favourable policies

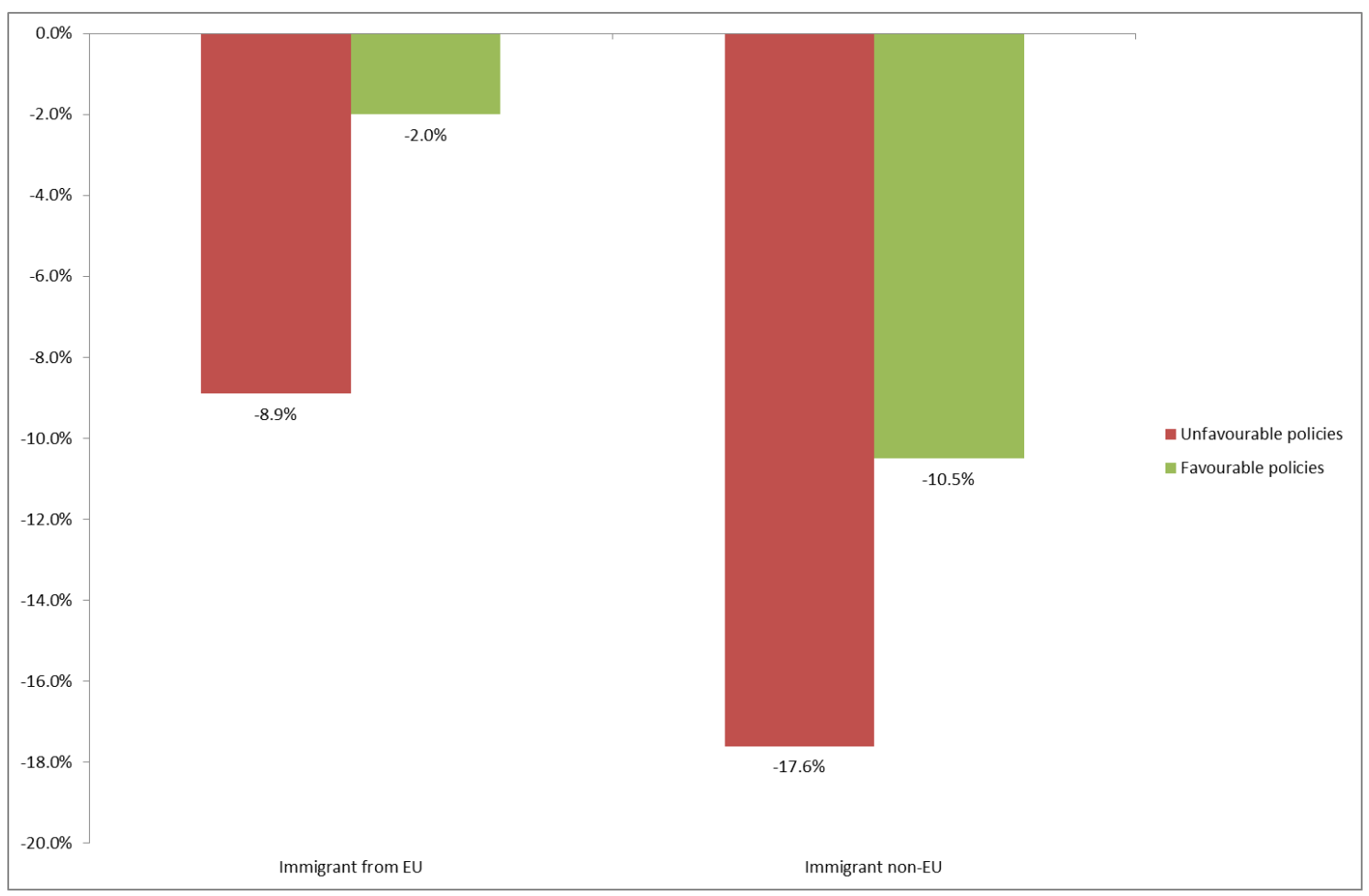

Wage differentials shown in Figure 2 have been calculated assuming that native and immigrant workers have the same return on human capital (experience and schooling). But, are these returns different for natives and immigrants? Do they change in relation to whether the countries have favourable or less favourable policies? Figures 3 and 4, respectively, show the returns on schooling years and potential experience for natives, immigrants from other EU countries, and immigrants from non-EU countries, depending on whether they live in a country with favourable and less favourable policies. 
Figure 3. Returns on schooling years for native and immigrant workers in relation to more or less favourable policies

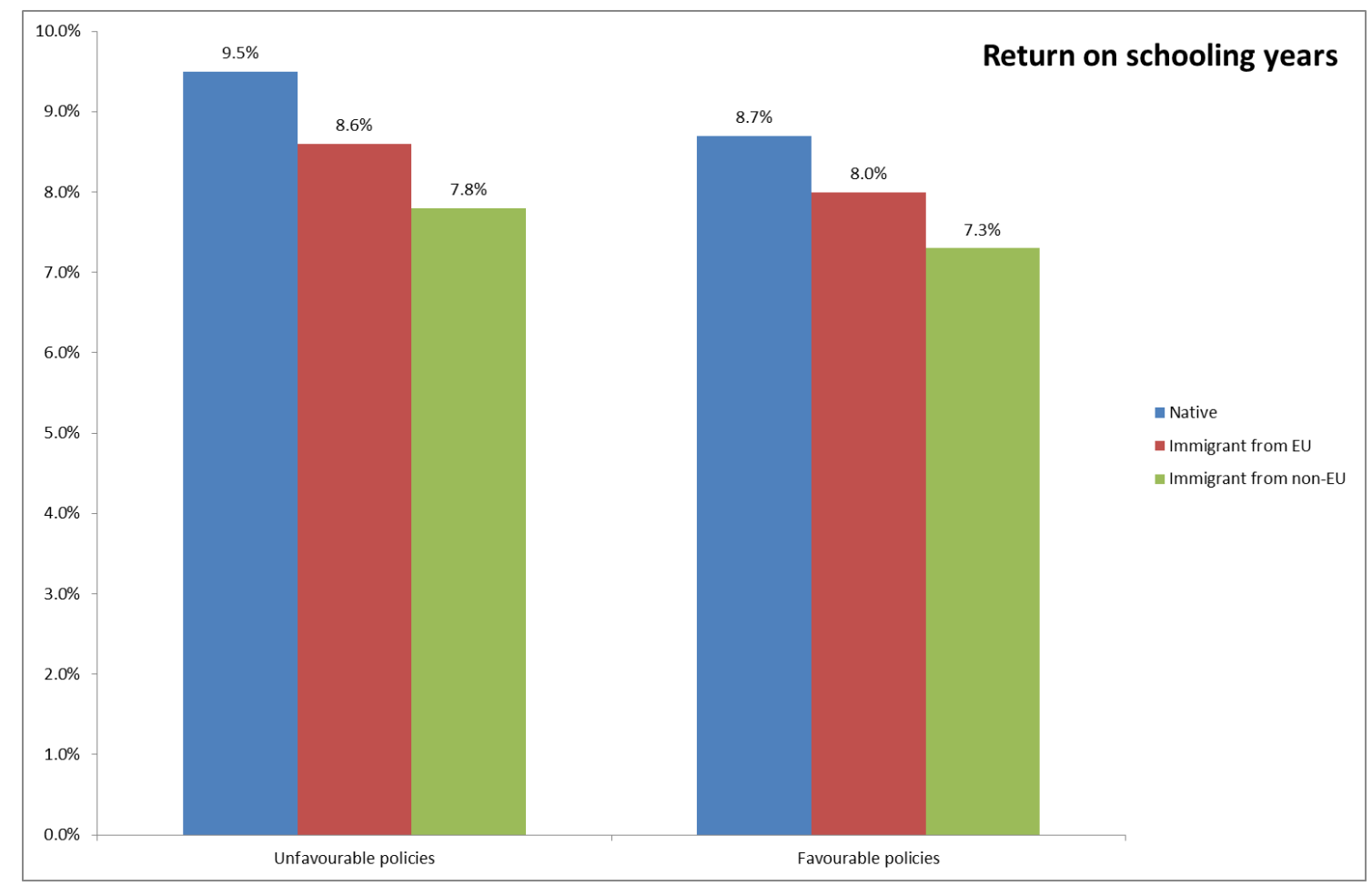

As can be seen in Figure 3, education has a positive and significant effect on both native and immigrant wages. Returns on years of schooling are around 9 percent (that is, one additional year of schooling increases wages by 9 percent) and they are higher in countries with unfavourable policies for all three of the groups of workers considered. Although surprising, this result is in line with the ones obtained by previous researchers, ${ }^{12}$ as returns on education are usually higher in those countries where the relative supply of educated workers is lower, as it is the case for most Central and Eastern Europe countries. In any case, and as expected, returns on schooling are always lower for immigrants than for natives in both groups of countries. As highlighted in the literature, ${ }^{13}$ this result is related to the limited transferability of education from home countries to the European labour markets.

12 Psacharopoulos and Patrinos, "A further update”, 112.

Psacharopoulos, "Returns to investment in education", Figure 2.

${ }^{13}$ Friedberg, "You can't take it with you", 222. 
Figure 4. Returns on experience for native and immigrant workers in relation to more or less favourable policies

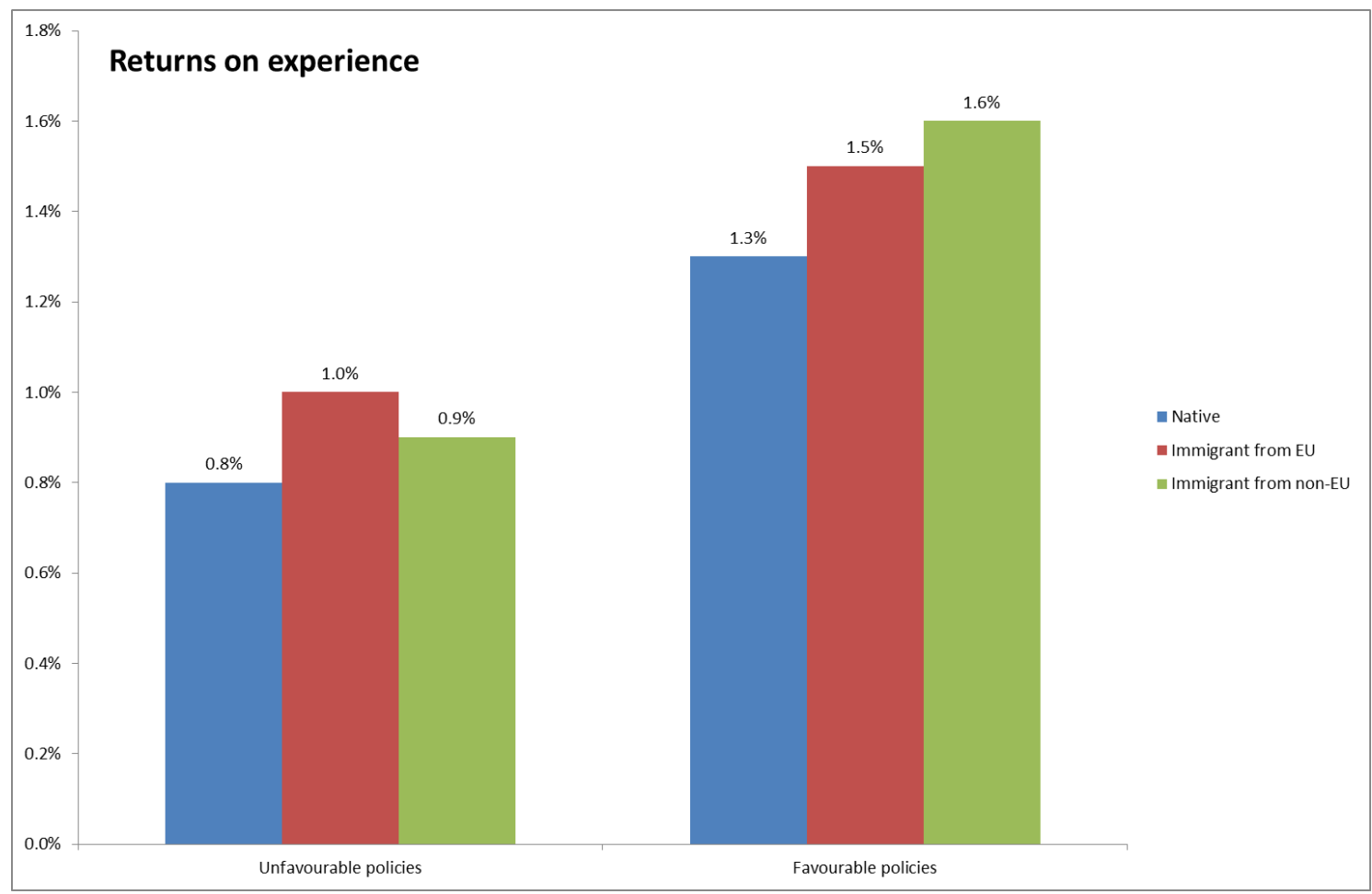

As can be seen from Figure 4, one additional year of experience increases wages by around 1 percent. Returns on potential experience are higher in countries with more favourable policies and, in both sets of countries, there is an additional return for immigrants, a result that is in line with the assimilation hypothesis already found in the literature. ${ }^{14}$ Furthermore, the return for immigrants in countries with more favourable policies isare clearly higher than for those in countries with less favourable policies.

In summary, the results show that wage differentials between immigrants and natives are lower in those countries with more favourable policies, and that this lower gap is mainly associated with higher returns on experience.

${ }^{14}$ Dustman and Glitz, "Migration and Education”, 362. 


\section{Final remarks}

The aim of this article was to analyse the role of favourable or unfavourable policies supporting the mobility of immigrants in EU labour markets. It has been shown that policies that favour human capital transferability improve the relative situation of immigrants in the labour market.

In order to identify countries with more favourable policies for the labour market integration of immigrants, data from MIPEX were used. There are two clear groups of countries: one formed by Austria, Belgium, Greece, Ireland, Italy, Luxemburg and the United Kingdom with less favourable policies and a second one formed by Germany, Denmark, Spain, Finland, France, Netherlands, Portugal and Sweden where policies are more favourable. In a second step, data from the EU Statistics on Income and Living Conditions (EU-SILC) were used to calculate wage differentials between immigrants and natives. The results show that wage differentials between immigrants and natives are lower in those countries with more favourable policies and that workers in these countries usually experience higher returns on experience (which allows for faster assimilation). However, given the kind of data used, it is not possible to disentangle which part of the effect is due to a particular measure or to other migration policies or even to 'non-migration policies'. This is an issue that will require further research.

From a policy perspective, and taking into account the previous caveat, the obtained results suggest that adopting migration-friendly policy measures reduces the native-immigrant wage gap. The approval of the 'Blue Card Directive' as an instrument for regulating highly skilled migration is certainly an important step forward to achieve a better integration of immigrant in European labour markets. While there are usually no recognition requirements for nonregulated professions such as IT specialists, foreign credential recognition is particularly relevant in the case of highly regulated professions. In fact, although EU Member States almost automatically recognise degrees obtained at any officially recognised university in the EU since 1975, regulations for third-country nationals depend to a great extent on internal rules. As shown by MIPEX data, there are still important policy differences between EU member states. Spreading best practices and promoting the exchange of information between member states will allow improving the situation of immigrants in the labour markets, although new directions for future guidance policy action are also required. 


\section{References}

Amuedo-Dorantes, C., and S. de la Rica. "Labor Market Assimilation of Recent Immigrants in Spain". British Journal of Industrial Relations 45, no. 2 (2007): 257-85.

Borjas, G.J. "Assimilation, Changes in Cohort Quality and the Earnings of Immigrants". Journal of Labour Economics 3, no. 4 (1985): 463-89.

Chaloff, J., and G. Lemaître. Managing Highly-Skilled Labour Migration: A Comparative Analysis of Migration Policies and Challenges in OECD Countries, OECD Social, Employment and Migration Working Paper No. 79. Paris: OECD Publishing, 2009.

Czaika, M., and H. de Haas. The effectiveness of immigration policies. A conceptual review of empirical evidence, DEMIG project paper no. 3. Oxford: International Migration Institute, 2011.

Docquier, F., and J. Machado. "Global competition for attracting talents and the world economy". World Economy, forthcoming (2015).

Dustman, C., and A. Glitz. "Migration and Education". In Handbook of the Economics of Education, edited by E. A. Hanushek, S. Machin and L. Woessmann: Vol. 4, chap. 4, 327-441. Amsterdam: North Holland, 2011.

Friedberg, R. "You can't take it with you? Immigrant assimilation and the portability of human capital". Journal of Labor Economics 18, no. 2 (2000): 221-51.

Jean, S., O. Causa, M. Jiménez and I. Wanner. "Migration and Labour Market Outcomes in OECD Countries". OECD Journal: Economic Studies (2010): 1-34.

Mahroum, S. "Europe and the Immigration of Highly Skilled Labour". International Migration 39, no. 5 (2001): 27-43. 
Psacharopoulos, G. "Returns to investment in education: A global update". World Development 22, no. 9 (1994): 1325-43.

Psacharopoulos, G., and H.A. Patrinos. "Returns to investment in education: a further update". Education Economics 12, no. 2 (2004): 111-34. 